\title{
Understanding the Impact of the Brand Experience on Brand Reputation by the Moderating Role of Technology Turbulence
}

\author{
Yağmur Özyer ${ }^{1}$ \\ ${ }^{1}$ T.C. Istanbul Arel University, Turkey \\ Correspondence: Yağmur Özyer, Department of Marketing, Faculty of Applied Sciences, T.C. Istanbul Arel \\ University, 34537 Turkey. E-mail: yagmurozyer@arel.edu.tr
}

Received: December 28, 2015 Accepted: January 13, 2016 Online Published: January 28, 2016

doi:10.5539/ijms.v8n1p161 URL: http://dx.doi.org/10.5539/ijms.v8n1p161

\begin{abstract}
Brand experience is the conceptualization of the brand's design, identity, packaging and connection that will remind the brand's perceptual, cognitive, emotional and behavioral reflections. In brand studies, mostly brand behavior, attitudes and feelings are analyzed. The brand experience arises not only under a general constraint or emotion situation but also in a more customized and detailed combination of feelings, perceptions, emotions and behaviors. This combination points out that brand consumers evaluate the brands and companies not only with the general sense or general behavior but also with more complex combinations. Brand's organizational reputation arises not only from brand's reputation of being a reliable brand, but also from emotional appeal, products and services, vision and leadership, workplace environment, which are also associated with factors such as social and environmental responsibility and financial performance. Brand experience influences the formation of this multifactorial brand reputation. The consumers in contact with the brand perceive the reputation of the brand they consume according to their experience in an environment where technology and market change constantly. This research examines the role of technological and market uncertainty which is a dimension of environmental uncertainty on the relationship between brand reputation and brand experience, which has emotional, behavioral and intellectual dimensions.
\end{abstract}

Keywords: brand experience, brand reputation, technology turbulence

\section{Introduction}

In today's highly competitive consumption environment, suppliers have realized and adopted the construct of offering satisfying experiences to customers across several channels with lower prices and sometimes with new launches. Interestingly, very few studies have imparted an understanding of brand experience. Academic research also validates the relevance of customer experience in smartphone brands (Grewal et al., 2009; Morganosky \& Cude, 2000; Otnes et al., 2012; Puccinelli et al. 2009; Srivastava \& Kaul, 2014; Verhoef et al., 2009).

Brand experience is conceptualized as a multi-dimensional construct and defined as "sensations, feelings, cognitions, and behavioral responses evoked by brand related stimuli that are part of a brand's design and identity, packaging, communications, and environments" (Brakus et al., 2009; Khan \& Rahman, 2015). Schmitt (1999) argued that there is a traditional approach to marketing view where consumers' decision-making process highlights excessively on the rational and logical elements of the decision, and propose to expand emotional and irrational aspects into the decision process. He noted that "experiential marketing is usually broadly defined as any form of customer-focused marketing activity, at various touch-points, that creates a sensory-emotional connection to customers" (Schmitt, 2009, 2008; Khan et al., 2015).

\section{Hypothesis Development}

According to Brakus et al. (2009), brand experience is quite different from concepts such as brand attitude, brand personality, brand involvement and brand attachment due to its involving cognition, sensation and feelings whereas other variables involve general assessments. However, researchers verify brand experience dimensions for several kinds of products (cars, laptops and sneakers) and explained their impact on brand loyalty through affective commitment (Iglesias et al., 2011). The concept of brand experience has been an interesting topic and many studies suggest that brand experience captures the real essence of customer-brand relationship (Brakus et 
al., 2009; Chang \& Chieng, 2006; Schmitt, 2009). In Brakus et al. (2009)'s research they analyzed "experiential brands" and consumer descriptions of brand experiences (both goods and service brands). According to the results of this study the researchers developed a brand experience scale. After these scale studies, Schmitt (2003) identified five different types of consumer experiences: sense, feel, think, act, and relate (Khan et al., 2015). "Sense" dimension in consumer experience involves bodily and touchable view of an experience, fascinating to five senses of sight, sound, scent, taste, and touch. There is a stimulation in "feel" to the consumers sensations and emotions where "think" fascinates the problem-solving experience. Behaviors, lifestyles, and interactions are the goals of "act" and individual's urges are the experiences that "relate" creates (Keller, 2013; Kim et al., 2015). Consequently, Brand Experience Scale (BES) has been developed and depending upon the consumers' experiences, the behavioral outcomes like brand loyalty and brand satisfaction linking to brand reputation are used to discover its importance (Brakus, Schmitt, \& Zarantonello, 2009; Zarantonello \& Schmitt, 2010). Therefore, based on above unrequited questions in brand experience, the need to do a study on its understanding will become quite clear with a case that examines consumers' experience on any smartphone brand.

The concept of "Experience Marketing" is first mentioned in the Harvard Business Review by Pine II and Gilmore (1998). In order to distinguish a product from its substitutions in the market, there should be some criteria such as function, efficiency, quality, and services where these are not enough in some points of high competitive environment. Hence a new concept is formed with a combination of brand and experience (Brakus, Schmitt, \& Zarantonello (2009). Brands recognize the advantage and importance of consumers' everlasting memories. Starting from this point of view, the experience helps anyone to develop trust, commitment, and preference through the brand (Ha \& Perks, 2005). However there are some characteristics seen in brand experience: it could be positive or negative, short-term or long-term, and have a positive effect on customer satisfaction, customer loyalty, and brand association; especially brand personality (Zarantonello \& Schmitt, 2010). An experience on brand is subjective and internalized by a relation to the consumer's actual use of products (Brakus et al., 2009) while the past experience with a product or brand leads to enhanced recall of brand information (Mikhailitchenko et al., 2009; Delgado-Ballester et al., 2012; Baumanna et al., 2015) Experiences can be conceptualized through social media and the content of any brand announced in social media has much more easily been understood by the owners efforts (cf. Simon, 1969; Lury, 2004). Thus, brand owners are able to articulate the brand and configure particular readings, and therefore experiences.

The experience economy theory involves experience marketing in general. According to Pine and Gilmore (1999), the customer participation and connection with the brand forms the economic value that lies in co-producing staged experiences. The dimensions of the brand experience consist of four first order constructs: sensory, affective, behavioral and intellectual experiences (Brakus et al., 2009, p. 52). Brand experience appropriates specific sensations, feelings, cognitions and behavioral responses; however, in Brakus et al. (2009) brand experience is proposed to be an antecedent of brand personality (Ishida \& Taylor, 2012). To position a brand in individual's/consumer's mind as an image, Hulten (2011) consider the companies to apply sensorial strategies which might differentiate and position a brand. Brand experience should affect not only past-directed satisfaction judgments but also future-directed consumer loyalty (Keng et al., 2013).

Beside the brand experience, positive brand reputation is becoming increasingly important for both academics and practitioners to be successful and hence profitable (Herbig \& Milewicz, 1995). Reputation is defined as aggregate perception of noticeable features of a brand/company from the perspective of external environments (Fombrun \& Rindova, 2000). While the brand reputation satisfies the consumer, the brand's acquisition over time also helps observers rank the brand in the market character (Veloutsou \& Moutinho, 2009). Having a good reputation will help attracting more customers but if it is repeatedly unsuccessful and cannot meet its stated aims or marketing signals, it will develop a negative reputation (Milewicz \& Herbig, 1994). Consumers perceive brands and companies as private affairs like celebrities or personalities that have their own character (Veloutsou \& Moutinho, 2009). The prediction about a brand will be much easier if the brand's current reputation is known by the target audience. There will be a damage of reputation when mixed signaling (saying one thing and doing another) occurs on a brand. When a brand does not deliver what it promises, customers will not perceive it as reliable and credible (Herbig \& Milewicz, 1995). Prior studies point out that constructive brand reputation protects the company during the crisis by creating a buffer or shelter (Hess, 2008). The service literature has extensive reinforcement about brand reputation and it has absolutely a positive effect in behavioral intentions of consumers (Gounaris \& Stathakopoulos, 2004). However highly reputed brands easily cope with the failure of service with their customers loyalty based on the past experiences and satisfaction. The brand experiences with its perceived reputation make the audiences believe this failure will not happen again in the future and cause higher behavioral intentions (Brady et al., 2008; Sengupta et al., 2015). In this study, the brand experience and 
reputation relation is examined focusing on the smartphone brands as implementation area. Accordingly it is hypothesized that;

H1: Sensory brand experience positively related to brand reputation.

H2: Affective brand experience positively related to brand reputation.

H3: Behavioral brand experience positively related to brand reputation.

H4: Intellectual brand experience positively related to brand reputation.

\subsection{The Moderating Role of Technology Turbulence}

Among dimensions of environmental uncertainty, technology turbulence is the most effective on the relationship between experience and reputation of a brand. It is defined as the rate of change in the composition of customers and their preferences by Jaworski and Kohli (1993). Managers of brands trying to be technology-oriented should be responsible of succeeding the correct signals of customers' latent needs. (Levitt 1969, Webster 1988, Jaworski and Kohli 1993). In order to have responsiveness in customers' changing preferences, organizations have to modify their products and services consistently if they operate with a more turbulent technology. Contrarily, in stable markets, an organization's products and services don't require any modification and the preferences of customers do not change very much. Therefore, brands operating in more turbulent markets like smartphone (evolving technology-intensive) sector are likely to have a greater need to be market and technology-oriented, compared to brands in stable markets (Jaworski and Kohli, 1993). Thus H5 is developed as:

H5: Technology turbulence shows a moderating effect between the relationship of brand experience and brand reputation.

\section{Research Design and Measures}

To test the above hypotheses, multi-item scales have been developed or adopted from prior studies for the measurement of variables. 5-point Likert scales ranging from "strongly disagree" (1) to "strongly agree" (5) have been used to measure all variables. The appendix includes the measures used in the study, followed by a summary of the measures. For the brand experience variable, the questionnaire items from Brakus et al. (2009) have been modified. Brand reputation is captured using three items based on Veloutsou and Moutinho (2009).

After developing the new questionnaire items in English, three academics from US-based universities evaluated the content and significance of the items to establish face validity. They did not note any difficulty in understanding the items or scales. The questionnaire items were then translated into Turkish by a bilingual researcher. During the translation process, the researchers discussed and calibrated our views and interpretations of the measurement items to generate a common conceptual basis. Then, we tested the suitability of the Turkish version of the questionnaire with 12 part-time graduate students who use smartphones and lots of applications on their phones. Respondents did not demonstrate any difficulty in understanding the items or scales.

The research's conceptual model, based on previous studies, is given in Figure 1, showing the impact of four antecedent factors - sensory brand experience, affective brand experience, behavioral brand experience and intellectual brand experience - on brand reputation. Brand experiences of smartphone consumers and its dimensions are hypothesized to have a direct influence on brand reputation. Technology turbulence is also hypothesized to moderate the relationship between brand experience and brand reputation. 


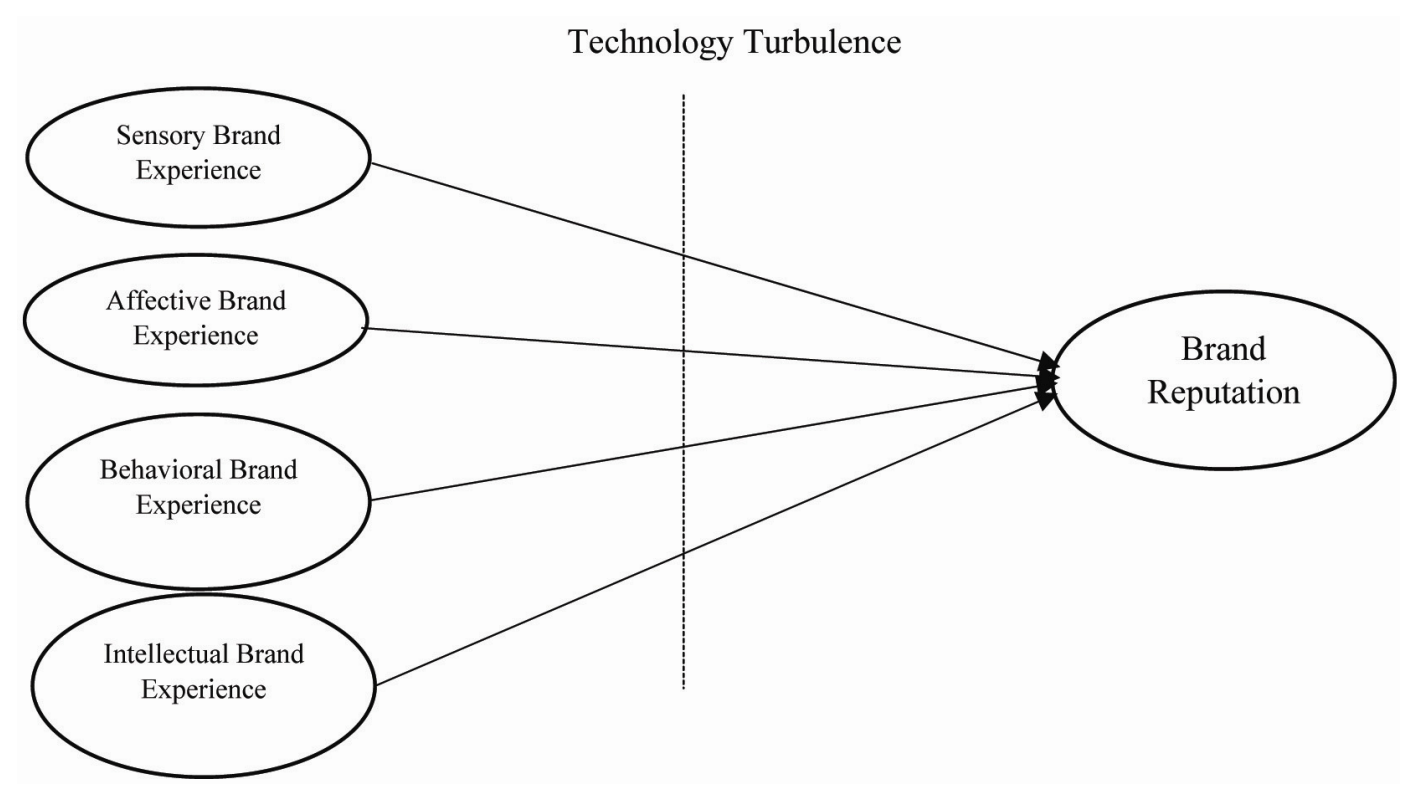

Figure 1. Proposed research design

\subsection{Sampling}

After developing the new questionnaire items in English, two academics from US-based universities evaluated the content and significance of the items to establish face validity. They did not note any difficulty in understanding the items or scales. These new and adopted questionnaire items were first translated into Turkish by a translator and then retranslated into English by a second translator using the parallel-translation method. The two translators then jointly reconciled all differences. A draft questionnaire was developed and then evaluated and revised in discussions with two academics from Turkey who has the knowledge of brand management as expert judges. Prior to the main survey activities, a pilot study was conducted with 35 respondents. The main survey, conducted in the Istanbul, Turkey focused on smartphone user consumers. Respondents were asked which smartphone brands they have any experience with (e.g., Apple iPhone, Samsung, $\mathrm{LG}$, etc.) prior to filling in the questionnaire. Using a convenience sampling method, a total of 181 questionnaires were collected and of these 15 were excluded due to incomplete or missing items. $48.0 \%$ of the respondents were males and $52 \%$ females. $28 \%$ of the respondents were between 16 and 25 years old, $21 \%$ between 26 and $35.25 \%$ between 36 and $45.14 \%$ between 46 and $55.10 \%$ between 56 and 65 , and $2 \%$ over 65 . On the other hand $46 \%$ of the respondents were Apple iPhone users, 30\% Samsung, $8 \%$ LG, 5\% Nokia, 3\% Blackberry, $2 \%$ Sony and $6 \%$ other brands.

\subsection{Measure Validity, Reliability and Hypothesis Testing}

After data collection, the reliability and validity of measures is evaluated by employing a purification process (Anderson \& Gerbing, 1988). Given the fact that brand experience scale is new, we first conducted an exploratory factor analysis including 20 measured items of three variables, using a principle component with a varimax rotation and an eigenvalue of 1 as the cutoff point. We found that the Kaiser-Meyer-Olkin (KMO) measure of sampling adequacy was 0.88 , and the Bartlett test of sphericity was significant at $\mathrm{p}<.01$, indicating the suitability of these data for factor analytic procedures. The result of the factor analysis suggests a six factor solution: sensory, affective, behavioral and intellectual brand experience, brand reputation and technology turbulence. Results reveal that Cronbach's Alphas for reliability are above the acceptable levels of .70 (Hair et al., 2006; Pallant, 2007).

After exploratory factor analysis, the reliability and validity of our variables is evaluated using confirmatory factor analysis (CFA) (Fornell and Larcker, 1981). To assess unidimensionality, measures were divided into three subsets of theoretically related variables: (1) the four brand experiences measures (i.e., sensory, affective, behavioral, intellectual), (2) technology turbulence and (3) brand reputation as recommended by Zarantonello \& Schmitt (2010), Veloutsou and Moutinho (2009) and Kohli and Jaworski (1993). After eliminating the problematic items through a step-by-step procedure, results indicated that three models fit adequately for the brand experience variables $(\chi 2=428.70, \mathrm{CFI}=.92$, RMSEA $=.08)$, technology turbulence variable $(\chi 2=463.02$, 
$\mathrm{CFI}=90, \mathrm{RMSEA}=.07)$, brand reputation $(\chi 2=165.38, \mathrm{CFI}=.91$, RMSEA $=.05)$. Also, all reliability estimates, including coefficient alphas, average variance extracted (AVE) for each construct, and AMOS-based composite reliabilities, are well beyond or close to the threshold levels suggested by Fornell and Larcker (1981). The reliabilities of the multiple-item, reflective measures are reported in Table 1, along with construct correlations and descriptive statistics for the scales. All reliability estimates are well beyond or close to the threshold levels suggested.

Table 1. Descriptive scales and construct correlations, and reliability estimates

\begin{tabular}{|c|c|c|c|c|c|c|c|c|c|}
\hline Variables & Mean & $\begin{array}{l}\text { Standard } \\
\text { Deviation }\end{array}$ & 1 & 2 & 3 & 4 & 5 & 6 & 7 \\
\hline 1. Brand Experience & 4.21 & 0.58 & 0.850 & & & & & & \\
\hline 2. D. of Sensory & 3.87 & 0.74 & $0.559 * *$ & 0.774 & & & & & \\
\hline 3. D. of Affective & 3.28 & 0.87 & $0.149 * *$ & $0.327^{* *}$ & 0.660 & & & & \\
\hline 4. D. of Behavioral & 3.91 & 0.82 & $0.328 * *$ & $0.182^{* *}$ & 0.075 & 0.762 & & & \\
\hline 5. D. of Intellectual & 3.71 & 0.82 & $0.264^{* *}$ & $0.214 * *$ & $0.130^{* *}$ & $0.527^{* *}$ & 0.926 & & \\
\hline 6. Brand Reputation & 3.71 & 0.85 & $0.115^{*}$ & $0.203^{* *}$ & $0.138^{* *}$ & $0.261^{* *}$ & $0.366^{* *}$ & 0.876 & \\
\hline 7. Technology Turbulence & 3.78 & 0.75 & 0.091 & $0.160^{* *}$ & 0.074 & $0.238^{* *}$ & $0.358^{* *}$ & $0.511^{* *}$ & 0.762 \\
\hline \multicolumn{3}{|l|}{ Cronbach Alfa } & 0.83 & 0.78 & 0.78 & 0.75 & 0.91 & 0.79 & 0.76 \\
\hline \multicolumn{3}{|l|}{ Composite Reliability(CR) } & 0.84 & 0.81 & 0.79 & 0.84 & 0.94 & 0.81 & 0.86 \\
\hline \multicolumn{3}{|c|}{ Average Variance Extracted (AVE) } & 0.51 & 0.52 & 0.53 & 0.68 & 0.63 & 0.59 & 0.57 \\
\hline
\end{tabular}

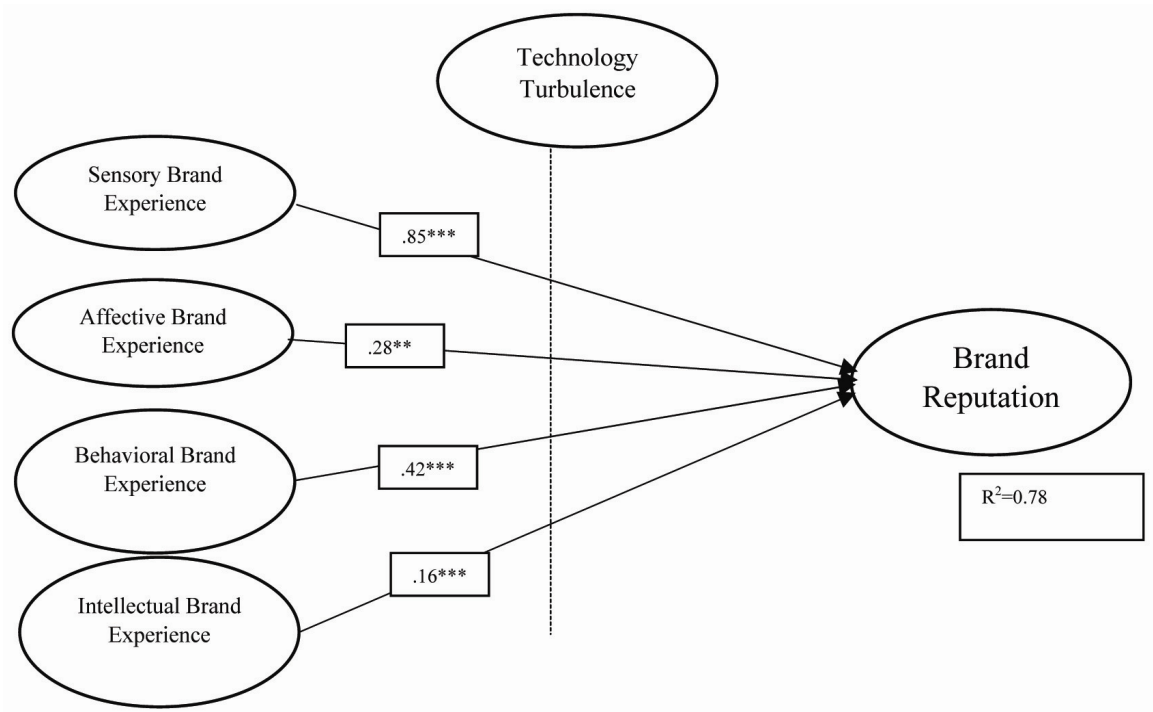

$\mathrm{X}^{2}(46)=119.54, \chi 2 / \mathrm{df}=2.60, \mathrm{CFI}=.94, \mathrm{IFI}=.94, \mathrm{RMSEA}=.08$

Notes. ${ }^{*} \mathrm{p}<0.1, * * \mathrm{p}<0.05, * * \mathrm{p}<0.01 ;$ Path coefficients are standardized

Figure 2. Path-model results

To test the hypotheses, a structural equation modeling (SEM) analysis is carried out using AMOS 22.0. SEM requires sample sizes greater than 200 with five to ten cases per observed variable (Kline, 2005; Hair et al., 2006). The original dataset consisted of 20 cases meeting the data adequacy requirements for SEM. Subsequent analyses resulted in a final dataset of 181 cases still exceeding the minimum requirements for SEM. During the analysis, the parameters representing the covariances across brand experience contents, brand reputation and technology turbulence variables were allowed to be free, consistent with the marketing literature. It has been found that the covariances among the brand experience variables were all significant. This indicates that sensory, affective, behavioral and intellectual brand experiences occur simultaneously and affect each other. Figure 2 demonstrates the relationships among brand experience, technology turbulence and brand reputation. It shows that the conceptual model adequately fits the data. The incremental fit index and comparative fit index are 
beyond 9 . The ratio ( $\chi 2$ /d.f.), the chi-square per degree of freedom, is 2.60 , which is less than 5 , suggesting a reasonable fit. The RMSEA is .08 .

Regarding the role of brand experience contents in brand reputation, it is found that sensory brand experience ( $\beta$ $=.85, \mathrm{p}<.01)$, affective brand experience $(\beta=.28, \mathrm{p}<.05)$, behavioral brand experience $(\beta=.42, \mathrm{p}<.01$ and intellectual brand experience $(\beta=.16, \mathrm{p}<.01)$ are positively associated with brand reputation, supporting $\mathrm{H} 1$, $\mathrm{H} 2, \mathrm{H} 3$ and $\mathrm{H} 4$.

Furthermore, the results in Figure 2 show that brand experience content variables explain $78 \%$ of variance (R2 $=.78)$ in brand reputation.

To test the moderating role of technology turbulence between brand experience and brand reputation (hypothesis H5), a moderated SEM analysis was used (Irwin and McClelland, 2001). Because of the possibility of multicollinearity, the technology turbulence, sensory, affective, behavioral and intellectual brand experience variables were mean-centered before performing the analysis, as suggested by Aiken and West (1991). Table 2 shows that the relationship between affective brand experience and brand reputation across low, medium, and high levels of technology turbulence $(\beta=.31, \mathrm{p}<.05)$ has an inverted U-shape ( $\cap$-shape). Also, the relationship between behavioral brand experience and brand reputation across low, medium, and high levels of technology turbulence $(\beta=.20, \mathrm{p}<.01)$ has an inverted U-shape $(\cap$-shape). The last dimension of brand experience is intellectual brand experience and brand reputation across low, medium and high levels of technology turbulence $(\beta=.23, \mathrm{p}<.01)$ However, no moderating role of any technology turbulence variable is found between the sensory brand experience and brand reputation, partially supporting H5.

Table 2. Moderating role of technology turbulence

\begin{tabular}{ll}
\hline Relationship & Technology Turbulence Path Model \\
\hline Sensory Brand Experience $\rightarrow$ Brand Reputation & $.22^{* * *}$ \\
Affective Brand Experience $\rightarrow$ Brand Reputation & $.30^{* * *}$ \\
Behavioral Brand Experience $\rightarrow$ Brand Reputation & $.24^{* * *}$ \\
Intellectual Brand Experience $\rightarrow$ Brand Reputation & $.23^{* * *}$ \\
Technology Turbulence $\rightarrow$ Brand Reputation & $.18^{* *}$ \\
(Technology Turbulence) $\rightarrow$ Brand Reputation & -.04 \\
Sensory Brand Exp.* (Tech. Turb) $)^{2} \rightarrow$ Brand Reputation & -.11 \\
Affective Brand Exp.* (Tech. Turb. $)^{2} \rightarrow$ Brand Reputation & $.031^{* *}$ \\
Behavioral Brand Exp.* (Tech. Turb. $)^{2} \rightarrow$ Brand Reputation & $.20^{* * *}$ \\
Intellectual Brand Exp.* (Tech. Turb.) ${ }^{2} \rightarrow$ Brand Reputation & $.23^{* * *}$ \\
& $\chi 2(87)=178.33, \chi 2 / \mathrm{df}=2.05$, CFI $=.95 \mathrm{IFI}=.95$, RMSEA $=.07$ \\
\hline
\end{tabular}

Notes. Tech. Tub.: Technology Turbulence, Brand Exp.: Brand Experience; Path coefficients are standardized; ${ }^{*} \mathrm{p}<0.1,{ }^{* *} \mathrm{p}<0.05,{ }^{* * *} \mathrm{p}<0.01$.

\section{Discussion and Implications}

First, this study empirically demonstrated the relationship between brand experience and brand reputation, enhancing the understanding of the niche of technology turbulence on this relationship. Given the fact that brand experience of smartphone users is conceptually distinguished from other brand attitude, they are more than general evaluative judgments including specific sensations, feelings, cognitions and behavioral responses through the smartphone brands. While previous studies focused on the role of brand experience on brand loyalty, consumer satisfaction, brand recall, brand trust, self image congruence, brand image (Brakus et al., 2009; Ishida \& Taylor, 2012; Baumann, 2015; Heath, 2006), this study searches for any relation with the brand reputation. Brand reputation is a crucial indicator for the brand equity (Alam \& Yasin, 2010). Thus, consumers frequently choose reputable smartphone brands based on their experience with the brand. If a smartphone brand (i) makes strong impression on consumer visual sense, appeals to consumer sense (i.e., sensory brand experience), (ii) induces feelings and sentiments, causes strong emotions through consumer (i.e., affective brand experience), (iii) results in bodily experiences and is action-oriented (i.e., behavioral brand experiences) and (iv) makes consumers think and stimulate their curiosity and problem solving, then, the consumers tend to see the brand more successful and valuable to purchase products continuously.

Specifically, when consumers have any experience with smartphone brands under the conditions of low or high technology uncertainty (i.e., more or less knowledge about the technology), the perceived image of the brand which called reputation is increases. However, when the technology turbulence is at a moderate level, consumers' experience on a brand makes the brand's reputation and equity stronger. Interestingly, contrary to the 
hypothesis, it is found that behavioral brand experiences impact brand equity with a " $U$ " shape. This finding shows that when the technology turbulence is at the moderate level, the affect of behavioral brand experience on the brand reputation is weak. However, when the consumer is exposed to too much or less technology turbulence, free expression of the behavioral brand experience strongly impacts a brand reputation.

Third, this study adds new insights to the brand management of the marketing literature. As mentioned before brand experience was associated with brand loyalty, brand image, and brand equity. This paper shows the importance of brand reputation as a brand management concept. This relation was measured by the moderating affect of technology turbulence on the smartphone brands. Future studies should be focused on other brand sectors and also can be related with other brand management issues such as brand heritage, communities, identification or advertising.

\section{References}

Aiken, L.S., \& West, S. G. (1991). Multiple regression: testing and interpreting interactions. London: Sage.

Alam, S. S., \& Yasin, N. M. (2010). The antecedents of online brand trust: Malaysian evidence. J. Bus. Econ. Manage., 11(2), 210-226. http://dx.doi.org/10.3846/jbem.2010.10

Anderson, J. C., \& Gerbing, D. W. (1988). Structural equation modeling in practice: A review and recommended two-step approach. Psychological bulletin, 103(3), 411. http://dx.doi.org/10.1037/0033-2909.103.3.411

Baumann, C., Hamin, H., \& Chong, A. (2015). The role of brand exposure and experience on brand recall-Product durables vis-à-vis FMCG. Journal of Retailing and Consumer Services, 23, 21-31. http://dx.doi.org/10.1016/j.jretconser.2014.11.003

Brady, T. F., Konkle, T., Alvarez, G. A., \& Oliva, A. (2008). Visual long-term memory has a massive storage capacity for object details. Proceedings of the National Academy of Sciences, 105(38), 14325-14329. http://dx.doi.org/10.1073/pnas.080339010

Brakus, J. J., Schmitt, B. H., \& Zarantonello, L. (2009). Brand Experience: What is It? How is It Measured? Does It Affect Loyalty?. J. Mark., 73(3), 52-68. http://dx.doi.org/10.1509/jmkg.73.3.52

Chang, P., \& Chieng, M. (2006). Building Consumer-Brand Relationship: Across-Cultural Experience View. Psychology and Marketing, 23(11), 927-959. http://dx.doi.org/ 10.1002/mar.20140

Delgado, E., Navarro, A., \& Sicilia, M. (2012). Revitalising brands through communication messages: the role of brand familiarity. European Journal of Marketing, 46(1/2), 31-51. http://dx.doi.org/10.1108/03090561211189220

Fombrun, C. J., \& Rindova, V. (2000). The Road to Transparency: Reputation. Management at Royal Dutch/Shell. In M. Schultz, M. J. Hatch, \& M. H. Larsen (Eds.), The expressive organization (vol. 7, pp. 7-96). Oxford: Oxford University Press.

Fornell, C., \& Larcker, D. F. (1981). Evaluating structural equation models with unobservable variables and measurement error. Journal of marketing research, 39-50. http://dx.doi.org/ 10.2307/3151312

Gounaris, S., \& Stathakopoulos, V. (2004). Antecedents and Consequences of Brand Loyalty: An Empirical Study. Journal of Brand Management, 11(4), 283-306. http://dx.doi.org/10.1057/palgrave.bm.2540174

Grewal, D., Levy, M., \& Kumar, V. (2009). Customer Experience Management in Retailing: an Organizing Framework. J. Retailing, 85(1), 1-14. http://dx.doi.org/10,1016/j.jretai.2009.01.001

Ha, Y. H., \& Perks, H. (2005). Effects of Consumer Perceptions of Brand Experience on the Web: Brand Familiarity, Satisfaction and Brand Trust. Journal of Consumer Behavior, 4(6), 438-452. http://dx.doi.org/10.1002/cb.29

Hair, J. F., Black, W. C., Babin, B. J., Anderson, R. E., \& Tatham, R. L. (2006). Multivariate data analysis (Vol. 6). Upper Saddle River, NJ: Pearson Prentice Hall.

Heath, R., Brandt, D., \& Nairn, A. (2006). Brand relationships: strengthened by emotion, weakened by attention. J. Advert. Res., 46(4), 410-419. http://dx.doi.org/10.2501/S002184990606048X

Herbig, P., \& Milewicz, J. (1995). The relationship of reputation and credibility to brand success. J. Consum Mark., 12(4), 4-10. http://dx.doi.org/10.1108/EUM0000000002601

Hess, R. L., Jr. (2008). The Impact of Firm Reputation and Failure Severity on Customers' Responses to Service Failures. Journal of Services Marketing, 22(5), 385-398. http://dx.doi.org/10.1108/08876040810889157 
Hulten, B. (2011). Sensory marketing: the multi-sensory brand-experience concept. European Business Review, 23(3), 256-273. http://dx.doi.org/10.1108/09555341111130245

Iglesias, A., Quiroga, S., \& Diz, A. (2011). Looking into the future of agriculture in a changing climate. European Review of Agricultural Economics, 38(3), 427-447. http://dx.doi.org/10.1093/erae/jbr037

Irwin, J. R., \& McClelland, G. H. (2001). Misleading heuristics and moderated multiple regression models. Journal of Marketing Research, 38(1), 100-109. http://dx.doi.org/10.1509/jmkr.38.1.100.18835

Ishida, C., \& Taylor, A. S. (2012). Reta1ler Brand Exper1ence, Brand Experience Congruence, and Consumer Satısfaction. Journal of Consumer Satisfaction, Dissatisfaction \& Complaining Behavior, 25, 63-79.

Jaworski, B. J., \& Kohli, A. K. (1993). Market orientation: antecedents and consequences. The Journal of Marketing, 53-70. http://dx.doi.org/10.2307/1251854

Keller, K. (2013). Strategic Brand Management: Building, Measuring, and Managing Brand Equity (4th ed.). UK: Pearson Publishing Inc.

Keng, C. J., Tran, V. D., \& Ti, T. M. L. (2013). Relationships among Brand Experience, Brand Personality, and Customer Experiential Value. Contemporary Management Research, 9(3), $247-262$. http://dx.doi.org/10.7903/cmr.11086

Khan, I., \& Rahman, E. (2015). Brand Experience Anatomy in Retailing: An Interpretive Structural Modeling Approach. Journal of Retailing and Consumer Services, 24, 60-69. http://dx.doi.org/10.1016/j.jretconser.2015.02.003

Kim, R., Yoon, D. H., Chao, Y., \& Dang, N. (2015). Effects of Brand Experience and Product Involvement on Brand Loyalty for Vietnamese Consumers. DLSUBusiness \& Economics Review, 25(1), 1-15.

Kline R. B. (2005). Principles and Practice of Structural Equation Modeling. New York, NY: Guilford Publications.

Levitt, T. (1969). The Marketing Mode. New York: McGraw-Hill.

Lury, C. (2004). Brands: The Logos of the Global Economy. Abingdon: Routledge.

Mikhailitchenko, A., Javalgi, R. G., Mikhailitchenko, G., \& Laroche, M. (2009). Crosscultural Advertising Communication: Visual Imagery, Brand Familiarity, and Brand Recall. J. Bus. Res., 62(10), 931-938. http://dx.doi.org/10,1016/j.jbusres.2007.11.019

Milewicz, J., \& Herbig, P. (1994). Evaluating the brand extension decision using a model of reputation building. J Prod Brand Manag, 3(1), 39-47.

Morganosky, M. A., \& Cude, B. J. (2000). Large Format Retailing in the US: a Consumer Experience Perspective. Journal of Retailing and Consumer Services, 7(4), $215-222$. http://dx.doi.org/10.1016/S0969-6989(00)00016-3

Otnes, C. C., Ilhan, B. E., \& Kulkarni, A. (2012). The Language of Marketplace Rituals: Implications for Customer Experience Management. J. Retail., 88(3), 367-383. http://dx.doi.org/10,1016/j.jretai.2012.02.002

Pallant, J. (2007). SPSS Survival Manual: A Step by Step Guide to Data Analysis Using SPSS for Windows. Maidenhead: McGraw-Hill.

Pine II, B. J., \& Gilmore, J. H. (1998). Welcome to the Experience Economy. Harvard Business Review, July-August, 97.

Pine II, B. J., \& Gilmore, J. H. (1999). The Experience Economy. Boston: Harward Business School Press.

Puccinelli, N. M., Goodstein, R. C., Grewal, D., Price, R., Raghubir, P., \& Stewart, D. (2009). Customer Experience Management in Retailing: Understanding the Buying Process. J. Retail., 85(1), 15-30. http://dx.doi.org/10.1016/j.jretai.2008.11.003

Schmitt, B. (1999). Experiential Marketing. Joumal of Marketing Management, 15, 53-67.

Schmitt, B. (2009). The Concept of Brand Experience. J. Brand Manag., 16(7), 417-419. http://dx.doi.org/10.1016/j.ism.2015.09.003

Sengupta, A. S., Balaji, M. S., \& Krishnan, B. C. (2015). How Customers Cope with Service Failure? A Study of Brand Reputation and Customer Satisfaction. Journal of Business Research, 68, 665-674. http://dx.doi.org/10.1016/j.jbusres.2014.08.005 
Shrivastava, P., \& Persson, S. (2014). A Theory of Strategy—Learning from China from walking to sailing. Management Review, 17(1), 38-61.

Simon, H. (1969). The Sciences of the Artificial. Cambridge, MA: MIT Press.

Smith, S. (2015). Conceptualising and Evaluating Experiences with Brands on Facebook. International Journal of Market Research, 55(3). http://dx.doi.org/10.2501/IJMR-2013-034

Veloutsou, C., \& Moutinho, L. (2009). Brand relationships through brand reputation and brand tribalism. Journal of Business Research, 62(3), 314-322. http://dx.doi.org/10.1016/j.jbusres.2008.05.010

Verhoef, P. C., Lemon, K. N., Parasuraman, A., Roggeveen, A., Tsiros, M., \& Schlesinger, L. A. (2009). Customer Experience Creation: Determinants, Dynamics and Management Strategies. J. Retail., 85(1), 31-41._http://dx.doi.org/10.1016/j.jretai.2008.11.001

Webster, F. E., Jr. (1988). Rediscovering the Marketing Concept. Business Horizons, 31(May-June), 29-39.

Zarantonello, L., \& Schmitt, B. H. (2010). Using the Brand Experience Scale to Profile Consumers and Predict Consumer Behavior. Journal of Brand Management, 17, 532-540. http://dx.doi.org/10.1057/bm.2010

\section{Copyrights}

Copyright for this article is retained by the author(s), with first publication rights granted to the journal.

This is an open-access article distributed under the terms and conditions of the Creative Commons Attribution license (http://creativecommons.org/licenses/by/3.0/). 